\title{
AS ORIGENS MOVIMENTISTAS DE POLÍTICAS PÚBLICAS: PROPOSTA ANALÍTICA APLICADA ÀS ÁREAS DE CRIANÇA E ADOLESCENTE, DIREITOS HUMANOS E SAÚDE ${ }^{1}$
}

\author{
Monika Dowbor \\ é professora do Departamento de Ciências Sociais da Universidade do Vale do Rio dos Sinos \\ (Unisinos).São Leopoldo,RS, Brasil E-mail:mdowbor@gmail.com \\ Orcid: 0000-0002-1845-046X \\ Euzeneia Carlos
}

é professora do Departamento de Ciências Sociais Universidade Federal do Espírito Santo.

Vitória,ES, Brasil.E-mail: euzeneiacarlos@gmail.com

Orcid: 0000-0003-0553-2746

Maria do Carmo Albuquerque

é pesquisadora do Núcleo Democracia e Ação Coletiva (NDAC) do Cebrap.

São Paulo, SP, Brasil. E-mail: mcarmoa@gmail.com

Orcid: 0000-0003-3026-3429

http://dx.doi.org/10.1590/0102-047080/105

\section{Introdução}

A literatura de políticas públicas indica que os produtores de políticas são gestores públicos, comunidades epistêmicas (Haas, 1992) e comunidades de especialistas (Kingdon, 1995). Na fronteira dos debates entre esse campo de estudos e o de movimentos sociais, mostramos neste artigo, do ponto de vista analítico e empírico, que os movimentos sociais não

\footnotetext{
${ }^{1}$ Este artigo é produto da pesquisa Efetividade dos movimentos sociais nas políticas públicas em perspectiva comparada, realizada com auxílio do Edital Universal 2014 do Conselho Nacional de Desenvolvimento Científico e Tecnológico (CNPq) e da Fundação de Apoio à Pesquisa e Inovação do Espírito Santo (Fapes). Versão preliminar foi apresentada no III Encontro Internacional Participação, Democracia e Políticas Públicas, realizado em Vitória (ES), em 2017. Agradecemos os comentários de Wagner Romão e as sugestões dos pareceristas anônimos da revista Lua Nova.
} 
são apenas desafiadores do status quo, mas também podem apresentar propostas concretas para as políticas públicas. Em geral a elaboração dessas propostas é invisibilizada porque realizada em períodos de latência, isto é, fora dos picos de mobilização. Trata-se de experiências-piloto, aqui entendidas por meio do conceito de inovação social, através das quais as organizações de movimentos geram soluções para os problemas identificados e para os quais não existem ainda respostas do poder público. Desenvolver uma inovação social é o primeiro passo que qualifica o movimento como propositor de alternativas a serem apresentadas a governos e que podem ser incorporadas como instrumentos de políticas públicas. $\mathrm{O}$ processo de elaboração de inovações, apresentação de alternativas e adoção de instrumentos é perpassado pela atuação estratégica de atores e por conflitos e disputas.

Neste artigo propomos uma sequência de categorias analíticas capaz de iluminar o processo de ação coletiva através do qual os projetos-piloto desenvolvidos por movimentos são adotados como políticas públicas. Para tanto, articulamos três conceitos de diferentes corpos teóricos - inovação social, alternativa e instrumento de política pública - que são usados pelas respectivas literaturas para iluminar apenas uma parte do processo em tela. Desse modo, a constatação empírica, baseada nos estudos de caso, de que os projetos-piloto e as experiências de movimentos sociais chegam a disputar a atenção de gestores e podem se tornar parte das políticas públicas é analiticamente reconstruída da seguinte maneira: como as inovações sociais desenvolvidas por movimentos sociais para atender a necessidades sociais (Mulgan et al., 2007) disputam a atenção de gestores públicos enquanto alternativas para os problemas públicos (Kingdon, 1995) e se tornam eventualmente instrumentos de políticas adotados pelos governos (Lascoumes e Le Galès, 2012).

Apesar de o artigo focar a atuação de movimentos sociais, o esquema analítico importa conceitos que pertencem a 
outros corpos teóricos, por não se encontrarem na literatura de movimentos sociais categorias capazes de iluminar o processo identificado empiricamente nos casos analisados. A primeira parte desse processo diz respeito às experiências-piloto, isto é, às atividades concretas que os atores de movimentos desenvolvem, traduzindo seus objetivos políticos em práticas sociais. A teoria de movimentos sociais não desenvolve uma abordagem para lidar com as fases de latência dos movimentos e, para analisar as experiências-piloto, buscamos o conceito de inovação social. Uma possibilidade seria usar o conceito de projeto político, de Evelina Dagnino, que se refere a um "conjunto de crenças, interesses, concepções de mundo, representações do que deve ser a vida em sociedade, que orientam a ação política dos diferentes sujeitos" (Dagnino, 2004, p. 144). Trata-se de um conceito capaz de identificar e sistematizar os conflitos em termos de crenças e valores nos processos mais amplos e de médio e longo prazo, mas não oferece o arcabouço analítico para capturar as experiências de menor alcance, especialmente suas formas de elaboração e sistematização. Essas dimensões são encontradas no conceito de inovação social, que permite iluminar detalhes da construção de práticas inovadoras, conforme veremos. O conceito de alternativas, por sua vez, provém de abordagens que buscam entender como as propostas de atores diversos se tornam políticas públicas. Esse tema está apenas começando a entrar no radar das análises de movimentos sociais, e o campo está iniciando as possíveis formas de análise. É o caso também do conceito de instrumentos de políticas públicas, de origem francesa, que traz para nosso arcabouço a possibilidade de olhar as políticas do ponto de vista de conflitos, interesses e valores, mas já como dispositivos adotados por gestores.

A articulação desses três elementos em sequência permite, por um lado, visualizar a atuação de atores coletivos que buscam traduzir em práticas sociais e políticas públicas 
seus objetivos políticos e, por outro, desnudar o processo de mudança nas políticas públicas. Isso porque valoriza o sequenciamento de episódios: inovação social (origem societal da proposta e seu caráter inovador), alternativa (reconhecimento pelos gestores) e instrumento (incorporação pelo Estado como dispositivo de política). Assim, para apreender o processo de mudança na política pública, impulsionado por formas societais de solução de problemas, faz-se necessário considerar desde a criação da inovação pelos atores sociais até sua transformação em instrumento de política, intermediado por seu reconhecimento pelos gestores como alternativa plausível e eficaz diante de outras opções.

$\mathrm{O}$ intuito deste artigo é mostrar que políticas públicas podem ter origem em movimentos sociais, em suas experiências inovadoras, e quando são reconhecidas pelos gestores como alternativas de política. Em outras palavras, as formas pretéritas de ação de atores coletivos contribuem para a mudança institucional e demonstram a incidência dos movimentos nas políticas públicas para além da pressão, mas não sem ela.

Empiricamente, este trabalho tem como base as campanhas de mobilização de três movimentos sociais, desenvolvidas ao longo dos anos 1990 e 2000: movimento de defesa da criança e do adolescente do município de São Paulo; movimento de direitos humanos do Espírito Santo; e movimento sanitarista nacional. Os movimentos sociais são descritos através de conceitos tradicionais das abordagens de efeitos políticos de movimentos, tais como campanhas de mobilização, oportunidades políticas e repertório de interação.

Grosso modo, a campanha é um momento de visibilidade das ações do movimento social voltadas a um objetivo comum, formada por um conjunto de episódios e eventos com sequenciamento, concatenados e constituintes do processo de ação coletiva (Tilly, 2006). Os casos analisados apresentam respectivamente: campanha pela municipalização da 
política socioeducativa, de 1999 a 2010; campanha contra a impunidade e violência, de 1993 a 2002; campanha pela formação de recursos humanos no Sistema Único de Saúde (SUS), entre 1996 e 2001. Por seu turno, as oportunidades políticas incluem incentivos e restrições à ação coletiva e a seus resultados, sendo cognitivamente percebidas pelos atores coletivos (McAdam, Tilly e Tarrow, 2001). O repertório de interação, por fim, equivale a estratégias e performances desenvolvidas pelo movimento no contexto de interação com os oponentes (Tilly, 2006), incluindo tanto as ações extrainstitucionais quanto as institucionais (Abers, Serafim e Tatagiba, 2014; Dowbor, 2012).

Operacionalizada mediante análise longitudinal e estudos de caso em profundidade, a pesquisa foi construída a partir de ferramentas do método qualitativo, como pesquisa documental no acervo de organizações do movimento e entrevista semiestruturada com ativistas em cada campanha. Em termos analíticos, o estudo enfatiza o processo de ação coletiva ao longo de um continuum temporal e sua influência na política pública, reconstruído através da articulação entre as categorias de inovação social, alternativa e instrumento.

$\mathrm{O}$ artigo segue estruturado em três seções: após esta introdução, a segunda seção discute as categorias analíticas mobilizadas; a terceira apresenta os estudos de caso à luz das categorias de movimentos sociais, delineando o modo de construção da inovação social, sua aceitação como alternativa e posterior incorporação como instrumento de política; por fim, discutimos os principais achados do estudo.

\section{Como estudar as origens movimentistas de políticas públicas? A sequência analítica de inovação social, alternativa e instrumento de política pública}

Esta seção explica como os conceitos de inovação social, alternativa e instrumento ajudam a iluminar a atuação de movimentos sociais que buscam transformar seus objetivos 
políticos em ações concretas, quer no âmbito da sociedade, quer na esfera de políticas públicas. Procuramos mostrar como a articulação dos três conceitos contribui para a reconstrução do processo que remete às origens movimentistas de políticas públicas.

\section{Experiências-piloto como inovações sociais}

Os movimentos sociais em seus períodos de latência (Melucci, 1996) desenvolvem atividades de bastidores, entre as quais a tradução prática de seus objetivos e reivindicações políticas em experiências concretas. De caráter local e/ou em formato de pilotos, esses projetos-piloto buscam resolver problemas sociais para os quais não existem ainda respostas estruturadas em serviços públicos ou aos quais o poder público nunca dedicou atenção. $\mathrm{O}$ conceito que melhor especifica esse tipo de experiência, a de colocar novas ideias em prática, é o de inovação social. Seu cerne consiste em circunscrever as experiências que buscam abranger necessidades sociais ainda não atendidas (Mulgan et al., 2007), o que corrobora o caráter reivindicativo e ao mesmo tempo inovador das propostas dos movimentos.

O conceito de inovação social começou a alimentar estudos a partir da década de 1990, e no Brasil sua expansão é mais recente (Ferrarini, 2016). A inovação social se diferencia da ideia de inovação tecnológica, utilizada por Schumpeter para analisar processos de inovação em países e empresas com foco na solução de problemas econômicos e maximização do lucro (Bignetti, 2011), ao passo que a inovação social permite analisar soluções políticas para demandas sociais, partindo do pressuposto de que as instituições e as políticas sociais existentes não atendem a todas as demandas postas e vocalizadas no mundo. Nessa lacuna, organizações, indivíduos e movimentos promovem ações que buscam maneiras de atender àquelas necessidades sociais. São inovações porque se trata de ações inéditas em um dado 
lugar, e são sociais porque se desenvolvem majoritariamente pelo esforço da sociedade civil e buscam resolver problemas sociais (Bignetti, 2011, p. 6; Mulgan et al., 2007, p. 8).

No Brasil, o conceito de tecnologia social se assemelha ao de inovação social. Cunhado a partir da crítica à inadequação das "tecnologias convencionais" solucionar problemas sociais, o termo compreende "produtos, técnicas e/ ou metodologias reaplicáveis, desenvolvidas na interação com a comunidade e que representem efetivas soluções de transformação social" (Dagnino, 2011, p. 1-2). Apesar da proximidade conceitual, o termo tecnologia nos remete à ideia da produção de bens concretos, máquinas ou equipamentos, os quais predominam na literatura sobre tecnologias sociais. É o caso das cisternas de captação de água (Costa e Dias, 2013). O conceito de inovação social possui vantagem em relação à tecnologia social na medida em que permite abranger um maior escopo de propostas e experiências (de programas, metodologias ou gestão em áreas sociais, currículos e cursos inovadores etc.), além de enfatizar o caráter propositivo que, no caso de movimentos sociais é especialmente relevante já que eles são frequentemente identificados como contestadores de status quo e raramente como produtores de políticas públicas. Para os casos aqui analisados, o conceito de inovação social é mais abrangente, pois evita uma compreensão restrita de tecnologia, e focaliza a entrada de novas ideias e processos (Hulgård e Ferrarini, 2010, p. 258). Assim, pareceu-nos útil a definição de inovação social de Chambon et al. (1982) (citado por Bignetti, 2011), a qual destaca quatro dimensões: sua forma; seu processo de criação e implantação; seus atores e os objetivos de mudança que busca atingir. Com respeito à forma, a inovação social tem a característica de ser imaterial, vinculando-se mais à ideia de serviços do que de produtos. Sua elaboração e realização pode incluir uma diversidade de atores das esferas estatal, societal e de mercado. O usuário não é visto 
como beneficiário ou cliente, mas como participante efetivo do processo. São produzidas com objetivos sociais e não de lucro.

Quanto aos objetivos e resultados das inovações sociais Bignetti (2011, p. 8) acentua sua diversidade, abrangendo modelos organizacionais, programas e princípios. Nesse sentido Hulgård e Ferrarini (2010, p. 258) destacam a criação de um "valor social, tal como o combate à pobreza, justiça social, acesso à água potável, democracia participativa e outros efeitos relativos a benefícios coletivos". Um quinto aspecto não mencionado por Chambon, mas apontado por outros autores, tais como Mulgan et al. (2007), essencial também na conceituação de tecnologia social (Dagnino, 2011, p. 1), é a difusão das inovações sociais e sua reaplicabilidade em oposição às inovações tecnológicas, que são mantidas sob segredo comercial.

Assim, consideramos que a inovação social se caracte54 riza por: (i) ser geralmente imaterial, vinculando-se centralmente à ideia de serviços, mas sem excluir produtos; (ii) processo de elaboração e realização incluindo diversidade de atores, com público-alvo participante efetivo; (iii) ter objetivos sociais e não de lucro; (iv) poder ser reaplicada e disseminada amplamente.

\section{Da inovação social à alternativa para política pública}

Observamos analiticamente os projetos desenvolvidos pelos movimentos sociais nos períodos de latência enquanto inovações sociais. Essas inovações resolvem problemas concretos em lugares pontuais e podem ser difundidas, mas não constituem políticas públicas, pois não conformam a ação de governo com vistas a resolver um problema público (Secchi, 2010). Uma inovação social pode se tornar uma ação de governo, mas essa passagem não é necessariamente simples ou direta. Conforme Kingdon (1995), para que isso ocorra é necessário que ela seja apresentada como alternativa viável 
aos tomadores de decisão quando estes buscam formas de resolver problemas presentes na agenda de governo. A inovação social precisa se tornar visível como solução de um problema público, isto é, atender a parâmetros que a tornem atraente dos pontos de vista técnico e político. A seguir, vamos delinear os principais elementos desse processo de transformação de inovações sociais em alternativas, baseando-nos nas proposições de Kingdon (1995) desenvolvidas para elucidar a etapa de especificação de alternativas do ciclo de políticas públicas ${ }^{2}$.

Para acompanhar analiticamente esse processo precisamos deslocar a atenção do movimento social, no primeiro momento, para focá-la na ação do governo. Se o governo está em busca de uma solução para dado problema, significa que esse problema foi incorporado à agenda governamental, isto é, ganhou destaque e atenção dos políticos e dos gestores públicos. É importante frisar esse ponto, pois tal situação constitui para os movimentos uma oportunidade política de apresentar sua forma de resolver dado problema público. Isso quer dizer que a inovação construída e experimentada pelo movimento pode passar a ser uma alternativa de política pública, na medida em que se propõe a resolver um problema presente na agenda de governo.

Não obstante, nem sempre a agenda governamental é predefinida ou precedente à apresentação de inovações sociais pelo movimento, cujas ações podem incidir sobre a incorporação de novos temas e problemas públicos ausentes na agenda política. Nessa situação, a elaboração de inovações pelos movimentos na solução de demandas públicas teria como resultado não somente a apresentação de alternativa de política, mas também a inclusão de novo problema na agenda governamental. Essa compreensão torna

\footnotetext{
2 Esta etapa é subsequente à de formulação de agenda do governo e anterior à de tomada de decisão. Kingdon elabora um esquema analítico e explicativo para a formulação de agenda e especificação de alternativas.
} 
o processo de formulação da agenda mais dinâmico porque sujeito à incidência societal. Em ambos os casos, o reconhecimento da inovação social como alternativa está condicionado à presença do problema na agenda do governo, seja predefinida pela "comunidade de especialistas" seja emergente do processo de ação coletiva.

Vamos imaginar que o acesso precário da população à saúde básica nas periferias de grandes cidades foi incorporado à agenda do governo. Esse problema obviamente já existia há muito tempo, mas estava fora do radar de interesse dos governantes. Na medida em que entra na agenda, diversos atores se mobilizam para apresentar suas formas de solucioná-lo: um programa de médico de família, equipes multiprofissionais, ou a contratação de empresas de saúde para fornecer planos baratos à população carente? Essas soluções correspondem a modos diferentes de entender a saúde pública e foram geradas por diferentes atores, que disputam a influência e incidência nos processos decisórios. Kingdon denomina esses atores genericamente de comunidade de especialistas (1995, p. 231) ${ }^{3}$, conceito que pode contemplar, mas não realça atores coletivos como movimentos sociais. Nosso ponto, quando focalizamos a atuação de movimentos no desenvolvimento de projetos, consiste em mostrar que no bojo dessas propostas concorrentes podem se encontrar também as inovações sociais dos movimentos apresentadas por eles como alternativas de políticas.

Para que as inovações operem como alternativas, elas têm que corresponder a alguns critérios objetivos e precisam ser apresentadas e divulgadas. Os critérios abrangem tanto a viabilidade técnica, quanto a congruência com os valores dos membros da comunidade de especialistas na área e com os limites orçamentários, além da aceitabilidade do público e

\footnotetext{
${ }^{3}$ Kingdon define a comunidade como grupo que compartilha a expertise em dada área, ainda que o conhecimento não implique comungarem da mesma visão do mundo nem das formas de como os problemas têm de ser resolvidos (1995, p. 231).
} 
receptividade dos políticos (Kingdon, 1995, p. 232). O preenchimento desses critérios é importante, mas não suficiente. As soluções precisam ser trabalhadas, apresentadas e defendidas como alternativas no momento em que a atenção do governo se volta para a busca de soluções para problemas presentes na sua agenda. Kingdon destaca analiticamente o papel de empreendedores de políticas (policy entrepreneurs) como aqueles que promovem as alternativas, estrategicamente, de diferentes formas e em diversos espaços, entre os quais audiências públicas, informações vazadas para a imprensa, circulação de papers e discursos (1995, p. 231). É mediante esse trabalho de divulgação e promoção que as soluções chegam aos tomadores de decisão, o que permite cotejar as alternativas para dado problema público. $\mathrm{Na}$ categoria de empreendedores políticos de Kingdon cabem também os militantes e as organizações de movimentos que, enquanto atores, se engajam em atividades visando apresentar suas inovações como alternativas aos gestores públicos.

Em suma, a agenda de governo, dotada de uma lista de problemas públicos, propicia oportunidade para a ação estratégica dos atores, individuais ou coletivos, no sentido de apresentar soluções para os problemas identificados. Para alcançar o estatuto de alternativa a ser considerada como plausível pelos tomadores de decisão, a proposta tem que corresponder a critérios técnicos e políticos e, ao mesmo tempo, precisa ser promovida, isto é, apresentada, divulgada e defendida pelos atores. Essas são condições para que uma inovação social desenvolvida por um movimento social seja transformada em uma alternativa. Em competição com outras alternativas, a proposta do movimento poderá ou não ser adotada pelos governantes e gestores públicos ${ }^{4} \operatorname{como}$ um instrumento de política pública.

\footnotetext{
${ }^{4} \mathrm{O}$ esquema analítico aqui apresentado não permite dizer qual das alternativas será de fato escolhida e transformada em instrumento de política pública, pois essa é uma etapa diferente, a de decisão política, regida por outras dinâmicas.
} 


\section{Políticas públicas como instrumentos}

Políticas públicas são comumente definidas como um conjunto de ações do governo que produzem efeitos específicos, desdobrando-se em planos, programas, projetos e sistemas de informação e pesquisa (Souza, 2006). Os diversos elementos que compõem uma política pública não são apenas técnicos, administrativos ou burocráticos, pois incluem visões de mundo e expressam relações de poder. Essa abordagem se apoia no conceito de instrumento de política pública, cuja seleção é profundamente política e produz efeitos estruturantes nas relações entre Estado e sociedade.

Para Lascoumes e Le Galès (2012), o conceito de instrumento ultrapassa os enfoques funcionalistas que o definem tão somente como um conjunto de técnicas à disposição dos governos para implementar seus objetivos políticos. Ao contrário, os autores concebem os instrumentos de política como perpassados por relações de poder e conflitos, portadores de valores, de uma interpretação do social e de concepções sobre o modo de regulação considerado. $\mathrm{O}$ instrumento é definido como "um dispositivo ao mesmo tempo técnico e social que organiza relações sociais específicas entre o poder público e seus destinatários em função das representações e das significações das quais é portador" (Lascoumes e Le Galès, 2012, p. 21). Embora muitas vezes associados à implementação da ação pública, os instrumentos podem também ser introduzidos em diversas etapas do ciclo de políticas como a formulação da agenda, o monitoramento e a avaliação.

Mas como se originam os instrumentos de políticas? Halpern e Le Galès (2011) argumentam que os instrumentos resultam em grande medida de processos de difusão e transferência entre Estados nas escalas nacional ou internacional. Os autores destacam ainda que a evolução dos instrumentos de política pública pode também ser originária do rearranjo de elementos preexistentes, aos moldes de 
uma combinação entre "velhos" e "novos" instrumentos. A análise longitudinal dos instrumentos e de sua evolução histórica permite captar suas raízes ao longo do tempo, identificando quando foram elaborados, selecionados e, neste último caso, integrados a um repertório de instrumentos pregressos que interage com o "novo".

Essas compreensões acerca da evolução dos instrumentos de políticas públicas colocam a necessidade de analisar sua origem, suscitando questões específicas de sedimentação, inércia e mudança institucional. Importa salientar que o Estado opera sob a influência de certo grau de reprodução institucional dado o legado histórico ou os instrumentos previamente institucionalizados. Todavia, isso não significa que o espaço para a introdução de novos instrumentos e de inovação seja inexistente. No processo de emergência de novos instrumentos ou de rearranjo com dispositivos preexistentes, Halpern e Le Galès (2011) destacam duas dimensões principais que afetam as possibilidades de os instrumentos produzirem mudanças nas políticas públicas: o grau de institucionalização do setor de política e a autonomia do setor em termos de consistência dos objetivos, competência administrativa, capacidade orçamentária e de organização. Grosso modo, essas diferenças institucionais entre os setores de políticas possuem implicações para a introdução dos instrumentos de políticas públicas.

Neste artigo, em vez de investigar o grau de institucionalização e de autonomia da política setorial, buscamos explorar a origem societal de alguns instrumentos. Nesse intuito, resgatamos a origem movimentista de certos instrumentos de políticas públicas, reconstruindo o processo de produção e de transferência de inovações sociais para a esfera governamental. Nesse processo, entre a construção da inovação social e sua incorporação como instrumento de política pública, o experimento alcança sua legitimidade quando reconhecido pelos gestores como alternativa. A articulação 
entre os conceitos de inovação social, alternativa e instrumento permite reconstruir o processo social por detrás da transformação de uma experiência de origem societal em instrumento de política pública.

\section{A origem movimentista de políticas públicas em três movimentos sociais}

Analisamos nesta seção três casos empíricos em que atividades desenvolvidas pelos movimentos como inovações sociais são elevadas ao estatuto de alternativas e depois adotadas como instrumentos de políticas públicas. Nos casos analisados, a produção de instrumentos de políticas oriundos de inovações sociais reconhecidas pelos gestores como alternativas ocorre no bojo de campanhas mobilizatórias de movimentos sociais, que desenvolvem suas ações intercalando períodos de visibilidade pública e de latência.

\section{A metodologia de atendimento nas Medidas} Socioeducativas em Meio Aberto

Analisamos aqui a contribuição do Movimento de Defesa da Criança e do Adolescente (MDCA) na criação de metodologias de atendimento a adolescentes que cumprem medidas socioeducativas em meio aberto (MSE/MA). Essa modalidade se constitui hoje em um conjunto de instrumentos integrantes da política de atendimento socioeducativo ${ }^{5}$, sob responsabilidade do município. Na cidade de São Paulo o atendimento socioeducativo em meio aberto se assenta em uma inovação social desenvolvida pelo MDCA, denominada Liberdade Assistida Comunitária (LAC).

Esse movimento social, desde o processo Constituinte e as lutas pelo Estatuto da Criança e do Adolescente (ECA),

\footnotetext{
${ }^{5}$ A política socioeducativa em meio aberto vem sendo municipalizada em todo o país, conforme definições do ECA (1990) e do Sistema Nacional de Atendimento Socioeducativo (Sinase, 2006), e integra a Política Nacional de Assistência Social (PNAS, 2004).
} 
se apoiou no ideário garantista, que tem como foco a redução drástica do confinamento de crianças e adolescentes em instituições, ressaltando o direito à convivência familiar e comunitária e, em consequência, o atendimento de adolescentes infratores em meio aberto e no município de residência da família.

Coerente com essa perspectiva, uma das organizações do movimento, a Pastoral do Menor, desenvolve desde os anos 1980 projetos de LAC, criando metodologias de atendimento fundadas no ideário garantista, que vê o adolescente como sujeito de direitos, e no papel fundamental da comunidade como meio para sua integração à sociedade.

Na cidade de São Paulo os projetos iniciais de LAC surgiram a partir das Comunidades Eclesiais de Base (CEBs), das quais participavam ativistas do MDCA (Santos, 2009, p. 24), e envolveram metodologias de trabalho comunitário, como a construção de vínculos com as famílias da região através de grupos de reflexão realizados em suas casas, onde se identificavam os problemas sociais da comunidade. Alguns adolescentes internados na antiga Fundação Estadual para o BemEstar do Menor (Febem) assim como suas famílias passaram a ser visitados por casais da comunidade (Santos, 2009).

A partir dessas iniciativas surge a LAC como método inovador de atendimento em meio aberto aos adolescentes que cumprem medidas socioeducativas. Enquanto inovação social, é composta por diversas metodologias e mecanismos de monitoramento, entre os quais se destacam, conforme Santos (2009, p. 31-54): (a) metodologia de acompanhamento do adolescente através de equipe multidisciplinar; (b) definição de formatos e conteúdos de oficinas coletivas; (c) metodologias de trabalho com a família e a comunidade; (d) procedimentos de relação com o judiciário e com os promotores públicos, incluindo a relação deles com a comunidade; (e) procedimentos de capacitação e de apoio psicológico para a equipe. Criou-se ainda uma ferramenta 
denominada "Proposta de Vida", uma planilha de planejamento e metas para os adolescentes, elaborada com a participação deles, dos técnicos e da família, com o objetivo de monitorar o cumprimento da medida e de subsidiar o juiz em sua avaliação sobre a oportunidade de encerramento da medida. Desenvolveram-se também metodologias de atuação em rede no território, incluindo a relação entre o programa das medidas (LAC) e outros programas públicos ou comunitários voltados à inserção do adolescente na vida social (Santos, 2009, p. 35). Assim foram criados mecanismos que se constituiriam no que hoje se denomina "rede de apoio no território".

A LAC foi desenvolvida inicialmente em algumas regiões de São Paulo, como Belém e Sapopemba, sendo posteriormente aplicada em outros estados, sob coordenação da Pastoral do Menor. Beneficiou-se das estruturas da Igreja e do apoio técnico com o qual ela conta, na pessoa de padres, 62 freiras e profissionais como assistentes sociais, psicólogos, educadores etc. A Pastoral contava também com a participação de técnicos da Febem, que contribuíram para que o desenho da proposta de LAC ganhasse adequação e viabilidade técnica (Paula, 2011; São Paulo, 2004; Passamani, 2006). Esses fatores possibilitaram a sistematização dessa inovação social que se consolidou em 2002, quando a Pastoral do Menor apresentou ao Conselho Nacional dos Direitos da Criança e do Adolescente (Conanda) e à Secretaria Especial de Direitos Humanos (SEDH/PR) um Projeto de LAC que veio a ser executado em 20 estados brasileiros, entre 2002 e 2007 (Pastoral do Menor, 2010).

Embora a política em meio aberto seja uma atribuição dos municípios desde o ECA (1990), a entrada dessa questão na agenda dos governos locais demorou muitos anos, marcados pelas normativas do Sinase. As normativas legais tornaram o tema progressivamente mais presente na agenda governamental. Contudo, não apresentavam o desenho de 
uma alternativa política, com os instrumentos necessários para sua implementação, nem criaram competências técnico-administrativas para executá-la em seus distintos âmbitos, seja o federal, estadual ou nas Secretarias Municipais de Assistência Social. Tais órgãos não possuíam normativas (leis, decretos, portarias) suficientes, nem agências públicas ou burocratas habilitados para executar a política, tampouco metodologias de execução, monitoramento e avaliação dessa política, ainda em gestação.

É nessa lacuna que a LAC, inovação social elaborada pelo MDCA, entra em pauta como alternativa de política, haja vista a presença da questão na agenda governamental. O movimento havia construído uma expertise sobre o acompanhamento de medidas em meio aberto, com conhecimentos e capacidades que os municípios não possuíam, constituindo-se assim numa "comunidade de especialistas" capaz de oferecer uma alternativa para a construção da política pública. Examinamos especificamente a contribuição da LAC para a política socioeducativa no município de São Paulo.

Na capital paulista, algumas organizações do MDCA, como a Pastoral do Menor e alguns Centros de Defesa da Criança e do Adolescente (Cedecas), entre outras, fundamentadas nas experiências de LAC, iniciaram no ano 2000 uma campanha pela municipalização da política de meio aberto. Constituíram uma organização chamada de Articulação, composta por organizações da sociedade civil que prestavam atendimento socioeducativo conveniadas com a Febem. Por seu lado, a secretária municipal de Assistência Social, Aldaíza Sposati, do Partido dos Trabalhadores (PT), também integrante da comunidade acadêmica que elaborou e lutou pela criação e implantação da PNAS, colocou em marcha a construção dessa política no município, aprovando em 2001 uma legislação específica, o Plano de Assistência Social da Cidade de São Paulo (PLAS), promulgada em 
2002-2003), e ganhando apoio das Conferências Municipais de Direitos da Criança e Adolescente e de Assistência Social. Chamou então, em 2003, um ativista do movimento, coordenador da Articulação, para coordenar o processo de municipalização da política. Caracteriza-se assim uma oportunidade política: o Executivo municipal, com sua nova composição político-partidária, era um aliado e reconhecia as metodologias elaboradas pelo movimento como alternativa na nova agenda de municipalização da política socioassistencial e socioeducativa. Dessas oportunidades surgiu uma coalizão de atores, constituindo-se uma "Comissão Interinstitucional" integrada pela Articulação e diversos órgãos governamentais coordenados pela Secretaria Municipal de Assistência Social (SAS). Essa Comissão elaborou, ainda em 2003, uma "Proposta de Municipalização" e um projeto-piloto para o meio aberto (São Paulo, 2004, p. 104), aprovado em 2004. A convocação da Comissão caracterizou um encaixe insti64 tucional que possibilitava maior acesso do movimento aos processos decisórios.

O projeto-piloto aprovado incorporava diversos elementos provenientes da metodologia de LAC para a política socioeducativa, especialmente as equipes multidisciplinares, os atendimentos grupais incluindo familiares, as visitas domiciliares, bem como a articulação com a rede local de serviços públicos e entidades comunitárias e a "Proposta de Vida" (São Paulo, 2004, p. 113).

A nova política instrumentalizada pela LAC não subsistiu por muito tempo no seu formato original. A então prefeita Marta Suplicy (PT) perdeu as eleições em 2004 e foi substituída por José Serra e a seguir por Gilberto Kassab, ambos do Partido da Social Democracia Brasileira (PSDB). Em decorrência, a oportunidade política se fechou, a coalizão de atores em defesa da política socioeducativa garantista no governo municipal se desfez e os atores do movimento deixaram de ocupar cargos no governo. O projeto-piloto foi 
executado em 2005, pelo novo governo - e se tornaram contínuas a partir de então as lutas da Articulação de entidades executoras do meio aberto para resistir ao desfiguramento do projeto original -, que atingiu duramente alguns instrumentos essenciais do modelo, como os recursos humanos e as rubricas orçamentárias destinadas ao trabalho com a família e comunidade. Nessas lutas sociais, vigorosas nos anos 2007 a 2010, a Articulação se apoiou nos fóruns do movimento, nos Conselhos Municipais de Direitos da Criança e Adolescente e da Assistência Social (CMDCA, Comas, Conselhos Tutelares), quando integrados por conselheiros defensores do paradigma garantista, assim como em alguns setores do Poder Judiciário, da Defensoria e do Ministério Público que defendiam as diretrizes garantistas. Nesse processo o movimento retoma as lutas para recuperar as diretrizes expressas pelos instrumentos provenientes da LAC, essenciais à sua visão garantista da política socioeducativa.

\section{O Movimento de Direitos Humanos e o Banco de Dados da Violência}

O Movimento de Direitos Humanos (MDH) do Espírito Santo possui um histórico de lutas sociais que remonta à década de 1980, com a criação, em 1984, do Centro de Defesa de Direitos Humanos da Serra (CDDH) e do Movimento Nacional de Direitos Humanos (MNDHLeste I). Na década de 1990 somam-se outras duas organizações, o Centro de Apoio aos Direitos Humanos (CADH) e o Conselho Estadual de Direitos Humanos (CEDH), além de grupos religiosos, sindicais e de partidos. Esse movimento se notabilizou na defesa dos direitos humanos pelo uso de um repertório de ação coletiva recorrente e histórico (Tilly, 2006), qual seja a denúncia fundada em relatórios, dossiês e bancos de dados. Técnicas de coleta de dados, arquivamento, sistematização e análise de documentos como matérias de jornais e depoimentos dão 
origem a dossiês, relatórios e bancos de informações que expressam o enquadramento interpretativo do movimento acerca da injustiça social e de suas soluções. A sistematização da informação acerca da realidade, sob o prisma dos direitos humanos, fez-se imperativa em diferentes contextos onde problemas e injustiças ocorriam de modo encoberto ou ocultado no (pelo) Estado, pela sociedade e pela mídia.

As técnicas e metodologias utilizadas pelo movimento na elaboração de denúncias fundadas em dados confiáveis da realidade social constituem inovações sociais, que se nutrem de experimentos, aprendizados e compartilhamentos de saberes populares acumulados ao longo da sua trajetória. Nesta seção identificamos o Banco de Dados da Violência desenvolvido pelo MDH do Espírito Santo durante a campanha contra a impunidade e violência como uma inovação social que, mediante seu reconhecimento pelo Estado como alternativa, se converte em instrumento de política pública.

Lançada em Vitória em 1993, pelo Movimento Nacional de Direitos Humanos (MNDH), a campanha emergiu contra o contexto generalizado de violência, impunidade e crime organizado. As bases de sustentação do crime organizado estavam em instituições do Estado (poderes Executivo, Legislativo e Judiciário) e da sociedade (Escuderie Detetive Le Cocq, União Democrática Ruralista-UDR e máfia do jogo de bicho). Conhecida no Espírito Santo como "Esquadrão da Morte”, a Le Cocq foi apontada como executora de vários assassinatos políticos, de líderes de movimentos sociais, ativistas de direitos humanos, sindicalistas rurais e políticos locais, além de crianças e adolescentes em situação de rua (Bittencourt, 2014). Pesam ainda contra essa organização paramilitar as acusações de obstrução de investigação de crimes, intimidação, ameaças e eliminação de testemunhas (MNDH-Leste I). 
Em sua origem, a campanha sustentou-se na articulação de uma rede de cerca de 40 entidades capixabas (movimentos sociais e populares, organizações de direitos humanos, sindicais, religiosas e partidos políticos), promotoras do Fórum em Defesa da Vida e do Fórum das Entidades do Campo e da Cidade (Carlos, 2014). Seu momento de maior visibilidade consistiu na criação do Fórum Permanente Contra a Violência e a Impunidade - Fórum Reage Espírito Santo, em 1999, que articulou setores da sociedade civil e da sociedade política. A campanha teve como principais desfechos, nos idos de 2000, o pedido de intervenção federal no estado, a Comissão Parlamentar de Inquérito (CPI) do narcotráfico e a dissolução do crime organizado representado pela Scuderie Detetive Le Cocq.

Em grande medida, as denúncias postuladas pelo movimento durante essa campanha tiveram como suporte as informações do Banco de Dados da Violência. Com base nele o movimento organizou diversas ações de posicionamento nos órgãos governamentais e audiências públicas, impetrando acusações e cobrando providências. A motivação para o desenvolvimento dessa inovação social residiu na falta de acesso ou na inexistência de estatísticas integradas, mapas e levantamentos nos órgãos estatais de justiça e segurança pública a respeito da violência, da impunidade e dos crimes insolúveis. O movimento identificava uma situação de grave injustiça, invisibilizada na sociedade e sobre a qual não havia informações sistematizadas e de livre acesso.

Denominado pelos ativistas como "Banco de Dados Sobre Violência - Perfil dos homicídios no ES”, sua metodologia foi desenvolvida na interação com diversas organizações do movimento de direitos humanos, ativistas e apoiadores. O projeto teve origem no MNDH, e no Espírito Santo foi coordenado pelo CDDH da Serra, com continuidade ao longo dos anos 1990. Seu primeiro relatório data de 1994, 
seguido por edições anuais do banco de dados ${ }^{6}$. A parceria com a Ufes fora firmada desde o início de sua implementação, conquanto restasse sem institucionalidade e dependente de iniciativas de alguns professores dos departamentos de serviço social, filosofia e geografia que o incluíram em seus projetos de pesquisa. À época o movimento reiterou o papel fundamental do Banco de Dados para corroborar as denúncias da campanha, que objetivava confrontar as estatísticas oficiais sobre a violência e instrumentalizar novas políticas públicas de garantia dos direitos humanos.

O movimento investiu em seminários e treinamentos de seus ativistas e apoiadores para análise dos dados do Banco, elaborado a partir de duas fontes principais: recortes de jornais e dados fornecidos pelo Instituto Brasileiro de Análise e Estatística (IBGE). O Banco de Dados permitiu um diagnóstico mais complexo sobre a violência no estado, em virtude do cruzamento de informações de diversas fontes jornalísticas. É um resultado notável, considerando que as estatísticas criminais da Política Civil e da Polícia Militar eram separadas, não havendo integração entre suas bases de dados.

O potencial de reaplicação é um traço dessa inovação social. Após o experimento inicial de sistematização pelos acadêmicos da universidade, o Banco de Dados da Violência passou a ser considerado pelo governo do Espírito Santo como uma alternativa a outras metodologias, sendo posteriormente convertido em instrumento de política pública. A aceitação governamental do Banco de Dados como alternativa e sua introdução como instrumento foram motivadas pela falta de credibilidade nas informações oficiais sobre violência e de unificação das fontes estatais das estatísticas criminais, afora sua viabilidade técnica, orçamentária e de recursos humanos. Mas não somente esses fatores pesaram

\footnotetext{
${ }^{6}$ Datam de 2 de dezembro de 1993 e de 4 de janeiro de 1994 as reuniões entre CDDH e MNDH onde se decidiu pela implementação do banco de dados sobre a violência, a ser desenvolvido pela campanha contra a impunidade e violência.
} 
na decisão, haja vista que ela ocorreu no contexto de oportunidades políticas, com a ocupação de cargos no governo e a formação de coalizões em torno da causa do movimento, ampliando a capacidade de influência do movimento nas decisões.

No primeiro aspecto, destaca-se a mudança da composição partidária no poder, a atuação de aliados poderosos no Estado como parlamentares e a abertura da agenda política governamental, retratando permeabilidade do Estado ao problema para o qual o movimento apresentava uma solução alternativa. No segundo, há ativistas do movimento em cargos públicos no Executivo: a ascensão de Vitor Buaiz (PT) ao governo do estado (de 1995 a 1998) foi acompanhada pela incorporação de ativistas dos direitos humanos em cargos públicos, como Perly Cipriano (PT) na condução da Secretaria Estadual de Justiça e Cidadania (Sejuc) e Ana Caracoche $(\mathrm{CDDH})$ no recém-criado Núcleo de Direitos Humanos (NDH), e pela atuação de parlamentares do PT na Assembleia Legislativa, como Claudio Vereza, Iriny Lopes e Brice Bragato ${ }^{7}$. Na culminância da campanha o movimento foi amparado por ampla rede de apoiadores formada pela coalizão reunida no Fórum Reage ES, composta por atores da sociedade civil e da sociedade política, sendo organizações civis, religiosas e partidos, ativistas na burocracia pública, aliados no Legislativo estadual e em setores do Judiciário.

A partir da transferência do Banco de Dados da Violência para o NDH da Sejuc, o dispositivo assume uma institucionalidade paulatinamente crescente. No primeiro momento (entre 1997 e 1998), os relatórios passam a ser elaborados no NDH, mantendo-se a assessoria acadêmica dos professores universitários já vinculados ao

\footnotetext{
7 Entrevistas concedidas para esta pesquisa em 26 de agosto de 2016, 21 de novembro de 2016, 2 de dezembro de 2016 e 15 de março de 2017.
} 
projeto. Em 1999 se formaliza um Termo de Cooperação Técnica entre Sejuc, Ufes e MNDH para elaboração do Banco de Dados da Violência. Na universidade o projeto foi sediado no Núcleo de Estudos, Pesquisa e Extensão sobre Violência, Segurança Pública e Direitos Humanos (Nevi) e em 2000 se institucionalizou como programa da Pró-Reitoria de Extensão (Proex). Os relatórios produzidos resultaram na publicação de dois boletins da Revista Cidadã. Na avaliação da coordenadora do projeto no Nevi, os relatórios do Banco de Dados ganharam em qualidade estatística e analítica, contribuindo com a instrumentação da política pública ${ }^{8}$.

No governo estadual, a unificação das estatísticas criminais em um banco de dados integrado, que agrega fontes diversificadas de órgãos da segurança pública, inclusive, em algumas situações, da Secretaria Estadual de Saúde (Sesa), consiste em importante resultado dessa conversão da inovação social em instrumento de política. Importante marco na instrumentação dessa política foi a criação do Centro Integrado Operacional de Defesa Social (Ciodes), em 2004, possibilitando a produção de um banco de dados único da Polícia Militar, da Polícia Civil, do Corpo de Bombeiros Militar, da Guarda Civil Municipal de Vitória, da Secretaria de Justiça e da Polícia Rodoviária federal. Achado desta pesquisa, o sistema integrado de informações criminais Ciodes possui "origem movimentista”, porque sua gênese está no Banco de Dados da Violência, uma inovação social elaborada pelo MDH-ES e, num contexto de oportunidades políticas, reconhecida como alternativa pelo governo e convertida em instrumento de política pública.

\footnotetext{
${ }^{8}$ Entrevista concedida para esta pesquisa em 12 de dezembro de 2016. No intuito de proteger o anonimato dos ativistas que concederam, será omitido o nome deles, aqui identificados somente pela data da entrevista.
} 


\section{Do país de doutores ao país de médicos: o Movimento} pela Reforma Sanitária e a formação de recursos humanos em saúde

A formação de recursos humanos para o sistema público de saúde pode soar como termo meramente técnico ou gerencial. Mas o Movimento pela Reforma Sanitária, em sua luta pelo acesso universal à saúde como direito dos cidadãos e dever do Estado, adotou essa estratégia desde o início de sua atuação, nos anos 1970. Os próprios ativistas eram formados em departamentos e cursos de perfil alternativo ao modelo de formação voltado para o prestigioso mercado de medicina liberal e sabiam que sem quadros preparados para atuar na especificidade da rede pública e seus usuários, o futuro sistema se tornaria frágil e vulnerável. Assim, ao longo de décadas desenvolveram atividades de formação alternativa em experiências-piloto ou na margem do sistema educacional. Duas delas se destacam: o Projeto Integração Docente-Assistencial (IDA), do início dos anos 1980, e o programa Uma Nova Iniciativa na Educação dos Profissionais de Saúde: união com a comunidade (UNI), do início dos anos 1970. A ideia desses projetos, que abrangiam poucas universidades, consistia em alinhar a formação dos futuros profissionais de saúde (universidades) às necessidades de saúde da população (comunidade) e dos serviços públicos (administração pública) dentro de uma visão preventiva, comunitária e coletiva de saúde (Pires-Alves e Paiva, 2006). Os projetos iam na contramão do modelo em vigência nas escolas de medicina, marcado pelo paradigma biologizante e curativo.

Em função da metodologia de trabalho do financiador, a Fundação Kellogg desde o início dos projetos programou um sistema de avaliação e sistematização, por meio de encontros anuais entre os coordenadores dos projetos em suas respectivas universidades (Barbieri, 2006, p. 49). Com a sistematização, os projetos se consolidaram como inovações sociais que 
expressavam a expertise do Movimento Sanitário na criação de uma proposta de formação dos profissionais de saúde com uma visão de saúde pública. Os encontros realizados se transformaram, influenciados pelo contexto da transição democrática e da mobilização do próprio Movimento pela Reforma Sanitária, em encontros anuais de debate e articulação política (Barbieri, 2006, p. 49), conformando um "movimento para a formação de novo profissional de saúde".

Em 1996, o movimento ganhou um impulso organizacional: durante o Seminário Nacional sobre a Formação de Recursos Humanos em Saúde se constituiu a Rede Unida. Foi proposto que a Rede passasse a incorporar não só os projetos, mas universidades, outras instituições de pesquisa e ensino e indivíduos interessados no tema. A relação com a Fundação Kellogg, os encontros de sistematização e avaliação dos projetos-piloto e a ampliação do movimento através da Rede Unida robusteceram a inovação social, conso72 lidando seu desenho de forma a convertê-la em "propostas inovadoras em formação e capacitação de recursos humanos" coerentes com os princípios do SUS e com pessoas que compartilhassem "o desejo de promover mudanças nos modelos de ensino e de atenção à saúde no Brasil” (Rangel e Vilasbôas, 1996, p. 16 e 18).

A possibilidade de mudança na política pública se abriu com a reformulação das diretrizes curriculares dos cursos superiores promovida pelo Ministério da Educação (MEG) e aberta à sociedade civil. A discussão sobre as novas diretrizes foi possibilitada pela reforma da Lei de Diretrizes e Bases da Educação (LDB), que culminou na Lei nº 9.394/1996. A reforma consistiu no abandono do sistema de currículos mínimos com detalhamento das disciplinas que deveriam compor cada curso e na adoção de linhas gerais capazes de definir quais as competências e habilidades se deseja desenvolver nos cursos em cada contexto. O MEC abriu, em 1997, um edital convidando as instituições de ensino superior e 
suas entidades representativas a apresentarem propostas para as novas diretrizes curriculares dos cursos de graduação que iriam substituir os rígidos currículos mínimos que pautavam a formação no país. O edital se constituiu em um ponto de acesso no qual o movimento criou um encaixe institucional de modo a influenciar o processo decisório.

A informação sobre a abertura do edital foi compartilhada numa das oficinas da Rede Unida, e o coletivo decidiu explorar essa oportunidade política ${ }^{9}$. Ao preparar a proposta, a Rede aproveitava o acúmulo das experiências já sistematizadas e compartilhadas dos projetos UNI e IDA para respaldar e legitimar sua proposta. A transformação dessa inovação social em alternativa de política pública ocorreu por meio da mobilização do movimento em uma campanha. A Rede Unida chamou para se posicionarem a favor de sua proposta importantes e reconhecidas organizações do campo, tais como a Associação Brasileira de Educação Médica (Abem), a Associação Brasileira de Enfermagem (ABEn), o Conselho Nacional de Saúde (CNS), a Coordenação de Recursos Humanos do Ministério da Saúde, o Conselho Nacional de Secretários de Saúde (Conass), o Conselho Nacional de Secretários Municipais de Saúde (Conasems) e diferentes universidades (Feuerwerker et al., 2000, p. 15), compondo uma rede maior de atores em defesa da pauta do movimento.

Não havia garantias no edital de que as propostas seriam de fato consideradas pelas Comissões de Especialistas do MEC, e estas - como logo percebeu a Rede Unida, que acompanhou o processo passo a passo - não levaram em conta as contribuições enviadas. A Rede exigiu mudança na composição das Comissões e, para tanto, recorreu à influência e posição institucional que o CNS tinha diante do Conselho Nacional de Educação (CNE). A negociação se desdobrou em convocação de audiências públicas apresentadas como

9 Entrevista concedida por Feuerwerker em 14 de setembro de 2012. 
exigência do setor de saúde. Por meio delas, o processo, antes limitado ao envio das propostas, tornou-se mais aberto à influência dos atores articulados em torno da Rede Unida.

Três anos depois, por decisão das instâncias competentes formadas pela Câmara de Educação Superior (CES) e pelo CNE, as diretrizes curriculares para o ensino em medicina, enfermagem e nutrição foram homologadas em 2001. As novas diretrizes refletiam o perfil de formação defendido e implementado nas duas experiências-piloto desenvolvidas pelos ativistas do Movimento Sanitário, cuja avaliação aponta "enormes coincidências" entre o aprovado e a proposta da Rede Unida (Almeida, 2001).

Em suma, a inovação social elaborada pelo movimento no que diz respeito à formação de recursos humanos para saúde foi apresentada às instituições do Estado em uma janela de oportunidade que consistiu na abertura de discussão das diretrizes curriculares dos cursos superiores com a sociedade civil. O movimento interferiu no processo decisório, aproveitando a permeabilidade do Estado por meio do repertório de interação (como audiências públicas) e ampliando suas redes de coalizão. Sua proposta foi aceita como alternativa de política, convertendo-se nas diretrizes curriculares, instrumento da política de formação de pessoal em saúde, coerente com a visão do Movimento pela Reforma Sanitária.

O objetivo geral das diretrizes não deixava dúvidas quanto ao redirecionamento da formação ao encontro das necessidades do SUS:

construir perfil acadêmico e profissional com competências, habilidades e conteúdo, dentro de perspectivas e abordagens contemporâneas de formação pertinentes e compatíveis com referências nacionais e internacionais, capazes de atuar com qualidade, eficiência e resolutividade, no Sistema Único de Saúde (SUS), considerando o processo da Reforma Sanitária Brasileiro (Parecer CNE/CES no 1.133 ). 
No caso dos cursos superiores, as linhas norteadoras dessa formação desenvolvida pelo movimento foram transformadas, em 2001, em diretrizes curriculares nacionais a serem seguidas em todos os cursos de medicina. O processo da implementação das diretrizes demandou outros instrumentos, adotados pelos ativistas do movimento quando estes foram ocupar cargos no Ministério da Saúde em 2003.

\section{Conclusão}

Esta análise explorou as origens movimentistas de certos setores de políticas públicas e os processos por meio dos quais as soluções desenvolvidas pelos movimentos como inovações sociais são elevadas ao estatuto de alternativas com reconhecimento público, donde deriva sua adoção como instrumentos de políticas públicas. Em termos analíticos, este artigo, ancorado nas abordagens de movimentos sociais, propôs a conexão entre conceitos de três literaturas diferentes. A principal vantagem dessa articulação é visibilizar um processo empírico que costuma ser estudado de forma segmentada. A abordagem de inovação social analisa práticas em que atores sociais desenvolvem soluções concretas para problemas. Essa atuação ocorre no que a literatura de movimentos sociais chama de períodos de latência, assunto que não recebe atenção analítica por parte dessa literatura. As inovações elaboradas pelos atores de movimentos ganham a luz do dia quando um governo, tendo definido sua agenda de problemas a resolver, busca propostas concretas, sistematizadas e viáveis. Essa etapa da produção de políticas públicas é chamada de especificação de alternativas e recebe um tratamento analítico sólido na abordagem de Kingdon (1995), a qual, no entanto, não enxerga nos movimentos sociais a autoria dessas alternativas, tampouco o faz na abordagem de instrumentos de políticas públicas. Não se trata de miopia, mas de especialização de áreas de conhecimento. Vale mencionar também que recorrer a outras literaturas 
nos pareceu frutífero na medida em que, junto com os conceitos, trazemos para a análise suas dimensões analíticas e principais processos já desenvolvidos por outros estudiosos. A articulação de conceitos, no sentido mais amplo, constrói pontes entre as ilhas do arquipélago da especialização de ciências sociais, conectando preciosos acúmulos analíticos.

Duas possíveis frentes de futuras agendas de pesquisa se abrem, a nosso ver, com a proposição sobre as origens movimentistas de políticas públicas. Em primeiro lugar, os casos aqui apresentados, apesar das diferenças nos setores de políticas públicas (nível da federação e características dos movimentos sociais), evidenciam as atividades do movimento desenvolvidas nos períodos de latência como altamente articuladas tanto aos seus objetivos políticos quanto às suas mobilizações. A construção dessas atividades mostra o processo de tradução dos objetivos políticos dos movimentos em experiências desenvolvidas pelos próprios atores societais, com destaque ao seu protagonismo no desenho e na vivência dessas práticas. Focar nesse tipo de atuação dos movimentos nos permite olhar para o período de latência não como momento de desmobilização, mas de criação, efervescência, inovação e produção cultural, intimamente ligado aos momentos de mobilização.

Em segundo lugar, a análise empírica aponta que a inovação social desenvolvida pelo movimento se converte em alternativa e desta em instrumento de política pública em contextos favoráveis de oportunidades políticas. Os casos mostram a importância da formação de redes mais amplas do movimento, com a inclusão de novos atores e organizações em torno de seu objetivo político específico, inclusive de segmentos da sociedade política. Com isso, os movimentos parecem aumentar as chances de influência de sua ação, pois a variedade de atores na coalizão não só atribui maior legitimação à sua atuação, mas propicia maior diversidade de estratégias e oportunidades de acesso ao Estado (Gurza Lavalle et al., 2017). Futuros 
estudos baseados em modelos de efeitos políticos de movimentos ${ }^{10}$ poderão mostrar a pertinência desse argumento.

Para além do esquema analítico aqui proposto, surge da análise um achado de caráter normativo. Os movimentos sociais possuem coerência entre os momentos de mobilização, nos quais erguem e agitam os estandartes de suas causas e objetivos políticos, e aqueles menos visíveis, nos quais produzem as ações que traduzem esses objetivos em soluções para problemas concretos. Trata-se de uma coerência que talvez possa inspirar outros atores políticos cuja legitimidade tem sido posta em questionamento, bem como chamar a atenção de gestores públicos para as alternativas que nascem da vontade de mudar o mundo.

\section{Monika Dowbor}

É doutora em Ciência Política pela USP e professora do Departamento de Ciências Sociais da Universidade do Vale do Rio dos Sinos (Unisinos), São Leopoldo, RS, Brasil. Orcid: 0000-0002-1845-046X

\section{Euzeneia Carlos}

É doutora em Ciência Política pela USP e professora do Departamento de Ciências Sociais da Universidade Federal do Espírito Santo (Ufes), Vitória, ES, Brasil.

\section{Maria do Carmo Albuquerque}

É doutora em Integração da América Latina pela USP e pesquisadora do Núcleo Democracia e Ação Coletiva (NDAC) do Centro Brasileiro de Análise e Planejamento (Cebrap), São Paulo, SP, Brasil.

\footnotetext{
${ }_{10}$ Para uma discussão das abordagens de movimentos sociais e seus resultados políticos, ver Carlos, Dowbor e Albuquerque (2017).
} 


\section{Bibliografia}

ABERS, Rebecca Neaera; SERAFIM, Lizandra; TATAGIBA, Luciana Ferreira. 2014. Repertórios de interação Estado-sociedade em um Estado heterogêneo: a experiência da era Lula. Dados, v. 57, n. 2, pp. 325-357.

ALMEIDA, Márcio José. 2001. Entrevista concedida. Olho Mágico, v. 8, n. 2. Não paginado. Disponível em: $<$ https://bit.ly/2CV4dAR $>$. Acesso em: 9 maio 2018.

BARBIERI, Fernanda Bersanetti. 2006. A rede Unida e o movimento de mudança na formação dos profissionais de saúde. $108 \mathrm{f}$. Dissertação de Mestrado em Saúde Coletiva. Londrina: UEL.

BIGNETTI, Luiz Paulo. 2011. As inovações sociais: uma incursão por ideias, tendências e focos de pesquisa. Ciências Sociais Unisinos, v. 47, n. 1, pp. 3-14.

BITTENCOURT, Matheus Boni. 2014. As políticas da insegurança: da Scuderie Detetive Le Cocq às masmorras do Novo Espírito Santo. $168 \mathrm{f}$. Dissertação de Mestrado em Ciências Sociais. Vitória: Ufes.

BRASIL. Ministério da Educação e Cultura. Parecer CNE/CES no 1.133, de 7 de agosto de 2001. Diário Oficial da União, Poder Legislativo, Brasília, DF, 3 out. 2001. Seção 1E, p. 131.

CARLOS, Euzeneia. 2014. Mudanças e continuidades no movimento de direitos humanos: padrões organizacionais, relacionais e discursivos. Opinião Pública, v. 20, n. 3, pp. 450-479.

CARLOS, Euzeneia; DOWBOR, Monika Weronika; ALBUQUERQUE, Maria do Carmo Alves. 2017. Movimentos sociais e seus efeitos nas políticas públicas: balanço do debate e proposições analíticas. Civitas, v. 17 , n. 2, pp. 360-378.

COSTA, Adriano Borges; DIAS, Rafael de Brito. 2013. Estado e sociedade civil na implantação de políticas de cisternas. In: COSTA, Adriano Borges (org.). Tecnologia social e políticas públicas. São Paulo: Instituto Pólis, pp. 33-64.

DAGNINO, Evelina. 2004. Construção democrática, neoliberalismo e participação: os dilemas da confluência perversa. Política $\mathcal{E}^{2}$ Sociedade, v. 3, n. 5, pp. 139-164.

DAGNINO, Renato Peixoto. 2011. Tecnologia social: base conceitual. Ciência Ẽ Tecnologia Social, v. 1, n. 1, pp. 1-12.

DOWBOR, Monika. 2012. A arte da institucionalização: estratégias de mobilização dos sanitaristas (1974-2006). 295 p. Tese de Doutorado em Ciência Política. São Paulo: Faculdade de Filosofia, Letras e Ciências Humanas, Universidade de São Paulo. 
FERRARINI, Adriane Vieira. 2016. O ethos da inovação social: implicações ético-políticas para o estudo de práticas produzidas em diferentes ambientes. Contemporânea, v. 6, n. 2, pp. 447-466.

FEUERWERKER, Laura Camargo Macruz et al. 2000. O processo de construção e de trabalho da rede Unida. Divulgação em Saúde para Debate, n. 22, pp. 9-17.

FÓRUM PERMANENTE CONTRA A VIOLÊNCIA E A IMPUNIDADE "REAGE ES". 2003. Relatório execuções sumárias, extrajudiciais ou arbitrárias. Vitória: Fórum Permanente Contra a Violência e a Impunidade "Reage ES".

GURZA LAVALLE, Adrian; CARLOS, Euzeneia; DOWBOR, Monika; SZWAKO, José. 2017. Movimentos sociais, institucionalização e domínios de agência. São Paulo: CEM, Texto para Discussão, n. 19.

HALPERN, Charlotte; LE GALÈS, Patrick. 2011. No autonomous public policy without ad hoc instruments: a comparative and longitudinal analysis of the European Union's environmental and urban policies. Revue Française de Science Politique, v. 61. n. 1, pp. 51-78.

HAAS, Peter. 1992. Introduction: epistemic communities and international policy coordination. International Organizations, v. 6, n. 1, pp. 1-35.

HULGÅRD, Lars; FERRARINI, Adriane Vieira. 2010. Inovação social: rumo a uma mudança experimental na política pública? Ciências Sociais Unisinos, v. 46, n. 3, pp. 256-263.

KINGDON, John Wells. 1995. Agendas, alternatives and public policies. New York: Harper Collins.

LASCOUMES, Pierre; LE GALÈS, Patrick. 2012. A ação pública abordada pelos seus instrumentos. Revista Pós Ciências Sociais, v. 9, n. 18, pp. 19-43.

McADAM, Doug; TARROW, Sidney; TILLY, Charles. 2001. Dynamics of contention. Cambridge: Cambridge University Press.

MELUCCI, Alberto. 1996. Challenging codes: collective action in the information age. Cambridge, UK: Cambridge University Press.

MULGAN, Geoff et al. 2007. Social innovation: what it is, why it matters and how it can be accelerated. London: The Young Foundation.

MOVIMENTO NACIONAL DE DIREITOS HUMANOS, REGIONAL

LESTE. 2002. Relatório do Movimento Nacional dos Direitos humanos sobre execuções sumárias, arbitrárias ou extra judiciais no Brasil. Vitória: Movimento Nacional de Direitos Humanos.

PASSAMANI, Maria Emília. 2006. A experiência de liberdade assistida comunitária na percepção de seus operadores. $176 \mathrm{f}$. Dissertação de Mestrado em Política Social. Vitória: Ufes. 
PASTORAL DO MENOR. 2010. Liberdade assistida: um projeto em construção. Belo Horizonte: Pastoral do Menor.

PAULA, Liana. 2011. Liberdade assistida: punição e cidadania na cidade de São Paulo. 275 f. Tese de Doutorado em Sociologia. São Paulo: USP.

PIRES-ALVES, Fernando Antonio; PAIVA, Carlos Henrique Assunção. 2006. Recursos críticos: história da cooperação técnica Opas-Brasil em recursos humanos para a saúde (1975-1988). Rio de Janeiro: Editora Fiocruz.

RANGEL SANTOS, Maria Lígia; VILASBÔAS, Ana Luíza. 1996. Rede Unida: breve histórico, concepção, organização e estratégias de ação. Divulgação em Saúde para Debate, n. 12, pp. 15-18.

SANTOS, Sueli Aparecida Santiago. 2009. Socioeducação: análise do programa socioeducativo da comunidade de Sapopemba. Trabalho de Conclusão de Curso de Pós-Graduação Adolescente em Conflito com a Lei, Práticas Profissionais. São Paulo: Uniban.

SÃO PAULO. Secretaria Municipal de Assistência Social. 2004. As medidas socioeducativas em meio aberto como garantia de proteção aos adolescentes $e$ jovens da cidade de São Paulo. São Paulo: SAS; SEDH.

SECCHI, Leonardo. 2010. Políticas públicas: conceitos, esquemas de análise, casos práticos. São Paulo: Cengage Learning.

SOUZA, Celina. 2006. Políticas públicas: uma revisão da literatura. Sociologias, v. 8, n. 16, pp. 20-45.

TILLY, Charles. 2006. Regime and repertoire. Chicago: University of Chicago Press. 


\section{AS ORIGENS MOVIMENTISTAS DE POLÍTICAS PÚBLICAS: PROPOSTA ANALÍTICA APLICADA ÀS ÁREAS DE CRIANÇA E ADOLESCENTE, DIREITOS HUMANOS E SAÚDE}

MONIKA DOWBOR

\section{EUZENEIA CARLOS}

MARIA DO CARMO ALBUQUERQUE

Resumo: Quem elabora as políticas públicas? Segundo a literatura sobre o tema, são os gestores públicos, as comunidades epistêmicas e de especialistas. Na fronteira entre esse campo e o de movimentos sociais, postulamos neste artigo que os movimentos não são apenas desafiadores do status quo, mas também podem ser propositores de alternativas para as políticas públicas. São discutidas e articuladas três categorias analíticas: inovação social, alternativa e instrumento de política pública, que ajudam a iluminar a atuação de movimentos que buscam transformar seus objetivos políticos em políticas públicas. Em seguida, aplicamos esse esquema analítico a três movimentos sociais - o de criança e adolescente, o de direitos humanos e o movimento sanitarista. Procuramos mostrar como a articulação desses três conceitos contribui para a reconstrução do processo que remete às origens movimentistas de políticas públicas.

Palavras-chave: Movimento Social; Política Pública; Instrumento; Alternativa; Inovação Social.

\section{PUBLIC POLICIES AND THEIR ORIGINS IN SOCIAL MOVEMENTS: AN ANALYTICAL PROPOSAL APPLIED TO CHILDREN AND ADOLESCENTS, HUMAN RIGHTS AND HEALTH}

Abstract: Who designs public policies? The public policy literature indicates that its producers are public administrators as well as epistemic and specialists communities. On the limits between 
this field and social movements, this article postulates that these movements are not only challengers of the status quo, but can also be proponents of alternatives to public policies. For such, it discusses and articulates three analytical categories: social innovation, alternative, and public policy instrument, which helps to clarify the actions of movements that seeks to transform their political objectives into public policies. Next, we apply this analytical scheme to three social movements - the children and adolescents movement, the human rights movement and the health movement. We show how the articulation between these three concepts contributes to the reconstruction of the process referring to social movement's origins of public policies.

Keywords: Social Movement; Public Policy; Instrument; Alternative; Social Innovation.

Recebido: $18 / 05 / 18 \quad$ Aprovado: $10 / 10 / 18$ 